\title{
The Evolution Arms Race of Garter Snakes and Newts
}

\author{
Richard Zhang ${ }^{1}$, Patricia M. Gray ${ }^{1}$ \\ ${ }^{1}$ University of Western Ontario, Department of Biology
}

\begin{abstract}
In evolutionary biology, predator-prey species pairs can be observed participating in evolutionary arms races between adaptations and counter-adaptations. For example, as a prey becomes more adept at avoiding capture, its predator becomes a more adept hunter. The rough-skinned newt (Taricha granulosa) produces a toxin that protects it from virtually all predators, except one. That one predator is the common garter snake (Thamnophis sirtalis), which has evolved resistance to this toxin. This predator-prey pair is seemingly engaged in a perpetual battle for higher toxicity and better resistance. While both adaptations come with costs, the coexistence of newt and garter snake imposes reciprocal selective pressure that drives this arms race.
\end{abstract}

KEYWORDS: Evolutionary Arms Race, TTX Resistance, Newt, Snake, Thamnophis sirtalis, Taricha granulosa

This essay is part of a continuing series of student class work completed in a second-year biology course at The University of Western Ontario, introduced here. The essay illustrates one or more principles of evolution on a topic of the student's own choice.

An evolutionary arms race is a form of coevolution that is the result of competition for better adaptations and counter-adaptations between a species pair. These arms races may occur between a predator and its prey or a parasite and its host. Adaptations within the pair of species may revolve around a trait (e.g. a toxin or virulence) that mediates the pair's interactions ${ }^{1}$. In a toxin-mediated arms race, the species pair typically comprises a toxic prey and a resistant predator ${ }^{1}$. Unfortunately, evidence for coevolution in toxin-mediated predator-prey interactions is often difficult to identify ${ }^{2}$. Complications include the presence of multiple predators as well as toxin-avoiding behaviours, where predators sample portions of prey to avoid lethal doses of toxicity ${ }^{2,3}$. Multiple predators can complicate the identification of specific traits that mediate interactions, as exemplified when plants can produce a myriad of possible compounds and phytophagous insects respond to suites of chemicals rather than individual chemicals ${ }^{2}$. Toxin-avoiding behaviours contribute to errors between estimates of toxin exposure and actual amounts consumed by a study's specimens ${ }^{2}$. For example, otters (Lutra lutra) in the Sierra de Gredos of central Spain consume only the internal organs and posterior of the Eurasian common toad (Bufo bufo gredosiciola), avoiding the toxins found in the head ${ }^{4}$. Fortunately, the species pair of the common garter snake (Thamnophis sirtalis) and the rough-skinned newt (Taricha granulosa) presents a toxin-mediated arms race that is exempt from these problems (Figure 1$)^{2}$. The common garter snake is the only known predator of the rough-skinned newt and swallows the newt whole, which prevents toxin-sampling behaviours ${ }^{2}$. Due to the simplicity of this interaction, many of the expectations theorized for toxin-mediated arms races have been observed between garter snakes and newts.

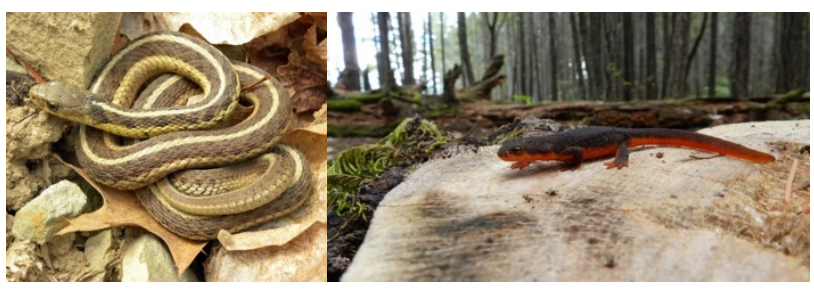

Figure 1 - The common garter snake (Thamnophis sirtalis) is shown on the left and the rough-skinned newt (Taricha granulosa), the snake's prey, is shown on the right ${ }^{5,6}$.

Where the two species are sympatric, the newt produces large quantities of tetrodotoxin (TTX), a neurotoxin with both broad and potent toxicity due to its high binding affinity for voltage-gated sodium channels in most animals ${ }^{1}$. Ingestion of the toxic newt leads to paralysis and death in other predators, but poses a low threat for the common garter snake, which evolved TTX resistance ${ }^{1}$. As a result, 
reciprocal selective pressures-imposed by newt and garter snake onto one another-drive the selection for greater toxicity in the newt and greater resistance in the garter snake.

In an arms race scenario, excessively superior adaptations in the presence of inferior counter-adaptations are not expected due to opposing selective forces that are caused by the costs these species incur from extreme adaptations. Instead, a close correspondence between the two opposing traits is expected where the arms race exists. The newt and garter snake's arms race acts accordingly within these expectations; it is disadvantageous to exhibit either excessive TTX quantities or TTX resistance. TTX resistance in the common garter snake comes with a genetically based trade-off for slower crawl speed ${ }^{8,10}$. In the absence of toxic prey, this is a tremendous cost to the snake's ability to evade predators and hunt prey. It is also costly to use energy and resources to produce more TTX than is needed. As a result, populations of garter snakes that interact with nontoxic prey have minimal TTX resistance, ${ }^{7,9}$. Similarly, populations of newt that interact with less resistant predators have lower levels of TTX . Geographic variation of TTX resistance between common garter snake populations shows two coevolutionary hotspots (areas of extremely high TTX resistance) separated by coldspots (areas of low TTX resistance; Figure 2) ${ }^{9}$. Nevertheless, TTX levels show a strong positive correlation with resistance ${ }^{9}$. Strong phenotype matching implies that resistance and toxicity must evolve together. It is also consistent with expectations that selection favours sufficient but not excessive resistance and toxicity.

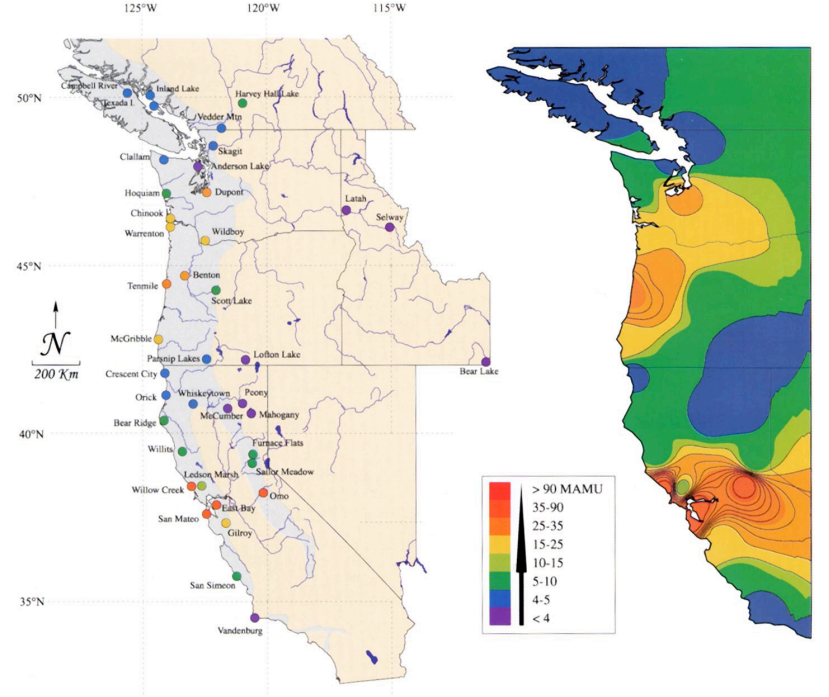

Figure 2 - The geographic distribution of TTX resistance in forty populations of Thamnophis sirtalis sampled from throughout western North America is shown on the left. The range of the genus Taricha is shown in grey. The map on the right shows two hotspots of extreme TTX resistance colour-mapped based on the dose of TTX required to reduce crawl speed by $50 \%$ in mouse-adjusted mass units (MAMU) ${ }^{9}$.

Another expectation is that a toxin severe enough to drive a predator-prey arms race should produce similar parallel arms races between multiple distinct species pairs, where the prey share the same toxin ${ }^{1,10}$. Thamnophis sirtalis is the first predator known to be coevolving with toxic newts, but the distantly related aquatic garter snake (Thamnophis couchii) also exhibits increased TTX resistance in response to another TTX-producing prey, the California newt (Taricha torosa) ${ }^{1}$. In sympatric populations of the aquatic garter snake and California newt, the TTX resistance of aquatic garter snakes is comparable with resistance in the common garter snake; only $10 \%$ of common garter snakes possess greater resistance ${ }^{1}$. Furthermore, the tradeoff that occurs in the common garter snake between crawl speed and TTX resistance is also present in these aquatic garter snake populations, which suggests similar underlying mechanisms for TTX resistance ${ }^{1}$. Phylogenetic evidence indicates that these mechanisms evolved independently, which means that TTX resistance evolved at least twice within separate garter snake species ${ }^{1}$. Phylogenetic evidence also shows at least two lineages with independent origins of TTX resistance within the species Th. sirtalis ${ }^{1}$. The existence of three separate lineages that each evolved TTX resistance emphasizes the importance of TTX toxicity as an evolutionary driving force in the predator-prey interactions of garter snakes and toxic newts ${ }^{1}$.

Parallel arms races can also indicate evolutionary constraints for possible adaptations to a prey's defences. Evolution is considered unconstrained when similar phenotypes have diverse underlying genetic mechanisms, but is likely constrained when these phenotypes have similar underlying genetic mechanisms ${ }^{10}$. The evolution of TTX resistance in garter snakes (Thamnophis) appears to be constrained towards the same genetic route. Protein sequence analyses of skeletal muscle sodium channels in Th. sirtalis, Th. couchii, and Th. atratusa third TTX-resistant garter snake-indicate that each species has evolved structural changes to skeletal muscle sodium channels that lower TTX- 
binding affinity ${ }^{10}$. These snakes all have amino acid substitutions in their skeletal muscle sodium channels at positions that determine TTX-binding affinity ${ }^{10}$. These substitutions decrease TTX-binding affinity, but also decrease sodium ion permeability, which accounts for the trade-off of slower crawl speed in more resistant snakes ${ }^{10}$. Because multiple origins of similar genetic changes are unlikely to be due to chance, the evolution of TTX resistance is probably predictable - at least within Thamnophis.

The struggles between TTX resistance and toxicity provide many insights regarding the strong reciprocal pressures that exist between arms race species. For instance, geographic patterns of resistance and toxicity demonstrate the strong positive correlation between these coevolving traits. Furthermore, the presence of distinct species pairs of garter snakes and toxic newts maintains that toxicity is a powerful driving force of evolution. Uniformity of the genetic paths (for TTX resistance) taken by three separate garter snake species indicates the presence of constraints on the evolution of TTX resistance. Altogether, the most valuable aspect of the arms race between the garter snake and the newt is that it provides a simple yet robust model of coevolution.

\section{References}

1. Brodie ED III, Feldman CR, Hanifin CT, Motychak JE, Mulcahy $\mathrm{DG}$, Williams BL, et al. Parallel arms races between garter snakes and newts involving tetrodotoxin as the phenotypic interface of coevolution. $J$ Chem Ecol. 2005; 31(2):343-356. DOI: $10.1007 / \mathrm{s} 10886-005-1345-x$

2. Hanifin CT, Yotsu-Yamashita M, Yasumoto T, Brodie ED III, Brodie ED Jr. Toxicity of dangerous prey: variation of tetrodotoxin levels within and among populations of the newt Taricha granulosa. J Chem Ecol. 1999; 25(9):2161-2175. DOI: 10.1023/A:1021049125805

3. Williams BL, Brodie ED Jr, Brodie ED III. Coevolution of deadly toxins and predator resistance: self-assessment of resistance by garter snakes leads to behavioral rejection of toxic newt prey. Herpetologica. 2003; 59(2):155-163. DOI: 10.1655/0018-0831(2003)059[0155:CODTAP]2.0.CO;2

4. Lizana M, Mellado VP. Depredación por la nutria (Lutra lutra) del sapo de la Sierra de Gredos (Bufo bufo gredosicola). Donana, Acta Vertebrata. 1990; 17(1):109-112.

5. Wikimedia. A rough-skinned Newt. Josephine county, Oregon [Internet]. 2015 [accessed 26 March 2017]. Available from: https://commons.wikimedia.org/wiki/File:RoughSkinned_Newt.JPG

6. Wilson M. Thamnophis sirtalis sirtalis (Eastern Garter Snake) in Spangler Park, Wooster, Ohio [Internet]. 2010 [accessed 26 March 2017]. Available from: https://commons.wikimedia.org/wiki/File:Thamnophis_sirtalis_ sirtalis_Wooster.jpg

7. Geffeney S, Brodie ED Jr, Ruben PC, Brodie ED III. Mechanisms of adaptation in a predator-prey arms race: TTXresistant sodium channels. Science. 2002; 297(5585):13361339. DOI: $10.1126 /$ science. 1074310
8. Brodie ED III, Brodie ED Jr. Costs of exploiting poisonous prey: evolutionary trade-offs in a predator-prey arms race. Evolution. 1999; 53(2):626-631.

9. Brodie ED III, Feldman CR, Hanifin CT, Motychak JE, Mulcahy DG, Williams BL, et al. The evolutionary response of predators to dangerous prey: hotspots and coldspots in the geographic mosaic of coevolution between garter snakes and newts. Evolution. 2002; 56(10):2067-2082.

10. Feldman CR, Brodie ED Jr, Brodie ED III, Pfrender ME. Constraint shapes convergence in tetrodotoxin-resistant sodium channels of snakes. Proc Natl Acad Sci USA. 2012; 109(12):4556-4561. DOI: 10.1073/pnas.1113468109 